\title{
Effects of early-life undernutrition in artificially reared rats: subsequent body and organ growth
}

\author{
BY J. L. SMART, R. F. MASSEY, S. C. NASH AND J. TONKISS \\ Department of Child Health, University of Manchester, The Medical School, Oxford \\ Road, Manchester M13 9PT
}

(Received 22 August 1986 - Accepted 24 March 1987)

\begin{abstract}
1. Four groups of rat pups were reared : mother-reared (MR) control (well-fed) and undernourished (MRC and MRU respectively) and artificially reared (AR) control and undernourished (ARC and ARU respectively). Pups for artificial rearing were fitted with a gastric cannula on postnatal day 5 and were fed, by intermittent gastric infusion, expressed rats' milk (days 5-7), mixtures of rats' milk and milk-substitute (days 8-16), and milksubstitute only (days 17-20). Solid food was available to MR pups throughout and to AR pups from day 14 . Undernutrition, imposed from postnatal days 5 to 25 , was effected initially by underfeeding the mother (MRU) or by infusing restricted quantities of milk (ARU). Weaning was at $21 \mathrm{~d}$ and undernutrition from day 21 to day 25 was by restricting the supply of solid food. All rats were fed ad lib. from $25 \mathrm{~d}$.

2. The developmental milestone, eye-opening, was delayed by undernutrition but unaffected by artificial rearing.

3. Growth curves in body-weight during the refeeding phase were influenced most by previous undernutrition and to a lesser extent (also negatively) by artificial rearing.

4. Fourteen measures of body and organ growth were taken at autopsy at 39 weeks. Twelve measures were affected by nutrition and only four by rearing (weight of whole body, epididymal fat pads, renal fat pads and adrenals).

5. AR rats had lighter epididymal and renal fat pads than MR rats perhaps due to the low fat content of the expressed milk they received early in artificial rearing.
\end{abstract}

In experimental studies with rats, undernutrition has very often been imposed during the suckling period, because that is the time of fast brain growth (brain growth spurt) when the brain is most vulnerable to nutritional insult, at least in terms of such gross measures as weight and cell number (Dobbing, 1981). It is well established that undernutrition at this time has a variety of sequelae that are irrecoverable even with prolonged refeeding; for example, a permanent stunting of body growth (Kennedy, 1957; Widdowson \& McCance, 1960), lasting deficits and distortions of brain growth (Dobbing \& Sands, 1971; Smart et al. 1974) and a number of lasting behavioural effects (Smart et al. 1973; Whatson \& Smart, 1978).

It is a problem for the interpretation of such effects, particularly the behavioural findings, that the undernutrition is imposed at a time when the young animal is dependent on its mother and this results, almost inevitably, in some alteration in the mother's care of her young (Smart, 1980). Some would go so far as to argue that the lasting behavioural effects of undernutrition during the suckling period can be attributed wholly to altered motheryoung interaction and without recourse to any direct effect of nutrition on growth and development (Levine \& Wiener, 1976). The argument can be extended to account for physiological effects, such as changes in pituitary-adrenal responsiveness, and even certain differences in brain development.

We have sought to avoid this problem of interpretation by removing the mother from the situation altogether and rearing the young artificially for most of the suckling period. Difficulties have been encountered in obtaining normal body and organ growth in rats artificially reared on milk substitutes (Smart et al. 1983, 1984), but we think that we have overcome these by using a regimen in which the pups are given expressed rats' milk for the first few days of artificial rearing and then changed gradually on to a milk-substitute which 
resembles rats' milk closely in composition (Smart \& Tonkiss, 1985; Tonkiss et al. 1987). In the present experiments normal, mother-reared (MR) and artificially reared (AR) rat pups were either well nourished or undernourished from postnatal day 5 to day 25 , after which all rats were well fed. We report here on the body growth of these animals to 39 weeks of age and on various body and organ measurements taken at that age. The results of three tests of behaviour on the same animals are reported briefly by Smart et al. (1987).

\section{METHODS}

Primiparous female rats of a black-and-white Lister stock were used. A partial split-litter design was employed, requiring about twenty litters to be born on the same day. Hence about 100 females were put with males overnight and vaginal smears taken in the morning to ascertain whether mating had taken place (gestational day 0 ). Age was standardized such that gestational day 22 was designated postnatal day 0 , whether or not litters were born after a $21 \mathrm{~d}$ or a $22 \mathrm{~d}$ gestation. Litters were reduced to ten pups on postnatal day 0 , and all remained with their own mothers until day 5.

Four treatment groups were created on day 5: MR control (well fed) and undernourished (MRC and MRU respectively) and AR control and undernourished (ARC and ARU respectively). There was littermate control within the $M R$ and within the $A R$ groups, but not across all four groups. The MR groups were created by fostering four to six male offspring of one well-nourished mother, two or three of them to another well-fed dam (MRC) and two or three to an underfed dam (MRU), all of which had given birth on the same day. Litters were made up to nine or ten pups with females from other litters. Food restriction of the undernourished mothers began in the 3rd week of pregnancy, so that their bodily reserves would be depleted before they received foster pups on postpartum day 5. Thus the undernutrition of these pups would be effective from the day of fostering. Underfed dams were given $12 \mathrm{~g} / \mathrm{d}$ of a good-quality diet (Porton Mouse Diet (PMD); K $\&$ K Greeff Ltd, Croydon, Surrey) from gestational day 14 to day $22,17 \mathrm{~g} / \mathrm{d}$ from postnatal day 0 to day $6,22 \mathrm{~g} / \mathrm{d}$ from day 7 to day 10 , and $25 \mathrm{~g}$ rising to a mean of $37 \mathrm{~g} / \mathrm{d}$ from day 11 to day 20 . From postnatal day 13 the amounts fed varied between mothers according to the growth of their litters. Throughout, the amounts represented about $60 \%$ of those taken by mothers fed ad lib. The true offspring of the underfed mothers were discarded on day 5.

Pups for AR were fitted with a gastric cannula on day 5 by the method of Hall (1975). They were taken from litters other than those used to create the MR groups and from each litter one male was ascribed to the ARC and another male to the ARU group. The AR method will be described only briefly here, except where it differs from that of Smart et al. (1983). The dietary regimen adopted was that devised by Tonkiss et al. (1987) whereby the AR pups are started off on expressed rats' milk and then changed gradually, from day 8 to day 17 , through a series of mixtures of rats' milk and milk-substitute, on to $100 \%$ milksubstitute. The collection and treatment of the rats' milk is described by Tonkiss et al. (1987). The method of preparation of the milk-substitute was as follows. A base was first produced from skimmed-milk powder and evaporated cows' milk through a dialysis step, to reduce the lactose content, and a freeze-thaw procedure to increase the protein concentration. Then maize oil, medium-chain triglycerides, vitamins, minerals and essential 
amino acids were added (N. S. Auestad, J. D. Bergstrom, Y. H. Ha and J. Edmond, unpublished results). The resulting milk-substitute closely resembled rats' milk in its gross and detailed composition, including the quantities of triglycerides to give medium-chainlength fatty acids and long-chain-length fatty acids in the ratio 33:67 by weight. Free lactose was present at $20-25 \mathrm{~g} / \mathrm{l}$, while the protein and amino acid content of the milk was formulated to produce an amino acid profile in serum very similar to that of MR pups (N. S. Auestad J. D. Bergstrom, Y. H. Ha and J. Edmond, unpublished results). The gross composition and physical properties of the milk-substitute were as follows $(\mathrm{g} / \mathrm{l})$ : protein 106 , carbohydrate 33 , fat 118 , osmolarity $342 \mathrm{mosmol} / 1$, pH 6.4 . Vitamins were present in the milk-substitute as constituents of its cows'-milk base and from an added vitamin mixture. These were thought to be more than adequate when the 'milk' is given in 'normal' quantities, but, to cover the possibility of deficiency in ARU pups receiving much smaller volumes of 'milk', a further vitamin supplement was added at the rate of $1 \mathrm{ml} /$ litre milksubstitute (Abidec multivitamin drops; Parke Davis \& Co., Pontypool, Gwent, (mg/ $\mathrm{ml}$ ): retinol $2 \cdot 00$, ergocalciferol 0.017 , thiamin $1 \cdot 67$, riboflavin 0.67 , pyridoxine 0.83 , nicotinamide $8 \cdot 33$, ascorbic acid $83 \cdot 33$ ). The mineral content of the milk-substitute was $(\mathrm{mg} / \mathrm{ml})$ : calcium $5 \cdot 04$, phosphorus $2 \cdot 65$, sodium $0 \cdot 6$, potassium $1 \cdot 12$, chloride $1 \cdot 41$, magnesium 0.2 , zinc 0.022 , iron 0.011 , copper 0.0063 .

Milk was delivered automatically by intermittent intragastric infusion (for $0.25 \mathrm{~h}$ in every $1 \mathrm{~h}$ ) in the amounts shown in Fig. 1 (p. 248). In total, ARU pups received $41 \%$ of the volume of milk received by ARC pups. All AR pups were housed individually in polystyrene tubs (Smart et al. 1983) floating in water-baths which were kept at $42^{\circ}$ from day 5 to day $13,38^{\circ}$ from day 14 to day 17 and $36^{\circ}$ from day 18 to day 20 . Each pup was given a fragment of solid PMD in its tub on day 14, more as a substrate to gnaw than as a source of nutrition, though, within a few days, many pups were consuming noticeable amounts. The fragments were replaced daily. From day 18 a mash made from powdered PMD and water (PMD-water 6:10 w/w) was made available to each AR pup in its tub. ARC pups were given about $4 \mathrm{~g} / \mathrm{d}$ and ARU pups $1.5 \mathrm{~g} / \mathrm{d}$, though this was not always all consumed even by the ARU animals.

On day 21 MR pups were weaned and AR pups had their cannula tubing snipped off flush with the body wall. All were housed two or three animals of like-treatment group per mouse cage $\left(0.29 \times 0.115 \times 0.12 \mathrm{~m}\right.$ high) over water-baths at $33^{\circ} . \mathrm{MRC}$ and ARC rats were given PMD mash and PMD pellets ad lib. MRU and ARU rats were given the same foods in restricted quantities which amounted to the equivalent of $2.5-4 \mathrm{~g}$ dry PMD/rat per d from day 21 to day 25 . All rats were transferred to larger cages $(0.41 \times 0.25 \times 0.2 \mathrm{~m}$ high $)$ on day 25 and were given pelleted PMD ad lib.

When these animals became adult their behaviour was tested in three situations, commencing at 18 weeks of age: open field, social behaviour and operant conditioning. These results are reported elsewhere (Smart et al. 1987). For the last test, from 34 to 37 weeks of age, rats were fed on restricted quantities of food to reduce them to and maintain them at $90 \%$ of their 34-week weight. After this they were allowed a period of 2 weeks' ad lib. feeding before they were killed for autopsy at 39 weeks. Body and organ measurements were obtained as described in Smart et al. (1983) and Tonkiss et al. (1985).

The rats were reared in two batches, 1 month apart, for which the results have been combined. There were fifteen MRC, ten MRU, thirteen ARC and ten ARU rats, drawn from a total of twenty-eight litters. 


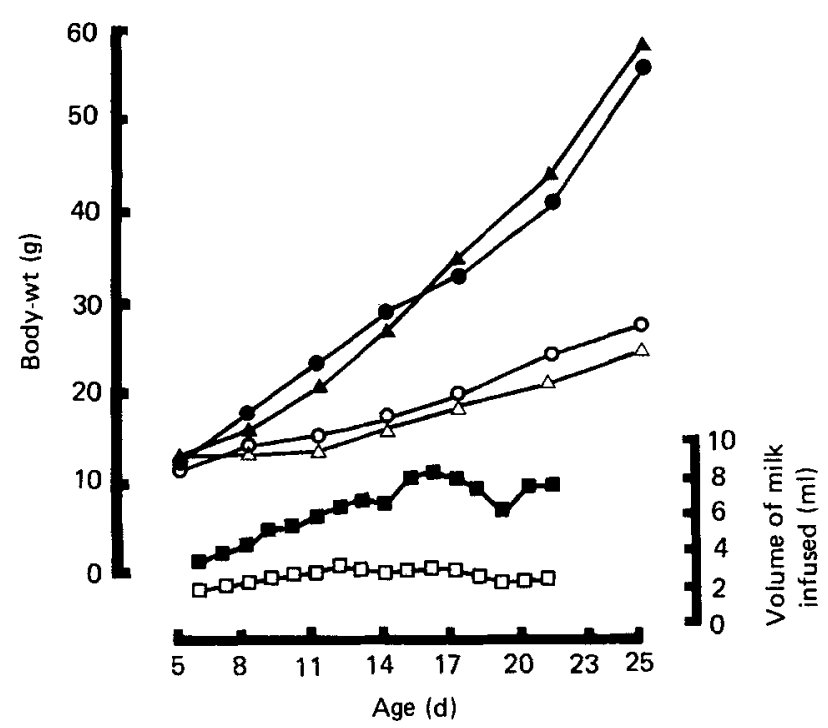

Fig. 1. Mean body-weight from 5 to $25 \mathrm{~d}$ of four groups of rats: (O), mother-reared control; $(O)$, mother-reared undernourished; $(\Delta)$, artificially reared control; $(\triangle)$, artificially reared undernourished. The volume of milk infused into artificially reared control $(\square)$ and undernourished $(\square)$ rats is also shown. The value of each point represents the amount of milk infused in the previous $24 \mathrm{~h}$. For details of rearing and nutrition, see pp. 246-247.

\section{Statistical analysis}

The growth curves in body-weight for the four groups were compared by trend analysis using multivariate analysis of variance (University of Manchester Regional Computer Centre, 1982), with three factors, namely, age, nutrition (well- or undernourished) and type of rearing (MR or AR). Such analysis provides information as to whether the curves describing changes in weight with age are 'parallel', whether the weight changes with age, and whether the overall mean values for weight, averaged across age, differ between groups. (The term 'parallel' is used here to mean 'a constant distance apart' and not in the strict mathematical sense which relates only to straight lines.) This analysis was done separately for the periods of undernutrition (5-25 d) and refeeding (35-119 d). The period beyond $119 \mathrm{~d}$ was not included because the intervals between weighings changed after that age. Age at eye-opening and the body and organ measurements taken at autopsy at 39 weeks of age were analysed by two-way analysis of variance (nutrition $\times$ type of rearing) using the default option of the Statistical Package for the Social Sciences. Pairs of values were compared by Student's $t$ test.

\section{RESULTS}

\section{Eye-opening}

The developmental milestone eye-opening was delayed by undernutrition $\left(F_{1,98}=37.503\right.$, $P<0.001)$, but was unaffected by AR $\left(F_{1,98}=0.026\right.$, not significant (NS); interaction component, $F_{1,98}=2 \cdot 604$, NS). Well-nourished animals had both eyes open about $1 \mathrm{~d}$ earlier than undernourished pups (mean values (d): MRC 13.83, MRU 14.91, ARC 14.08, ARU 14.58). 


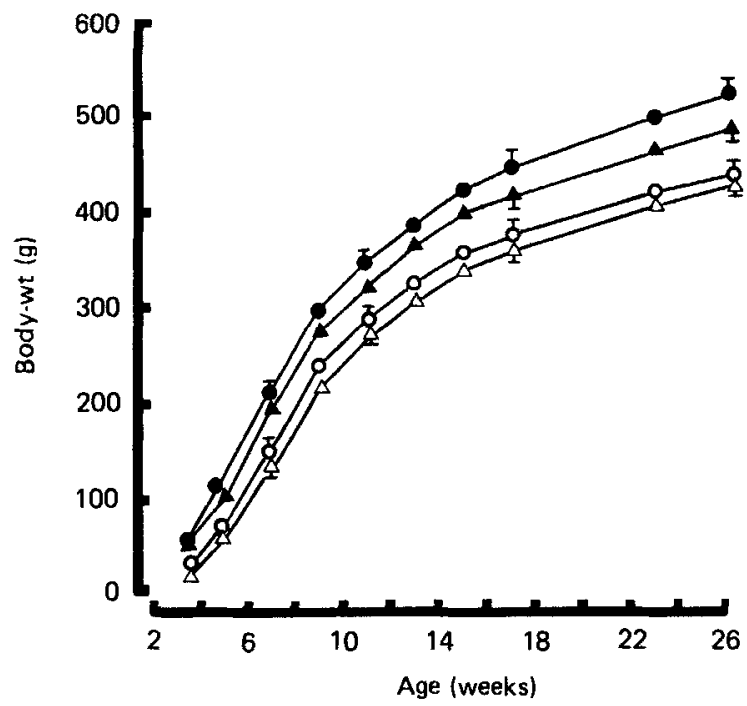

Fig. 2. Mean body-weight from 25 to $182 \mathrm{~d}$ of four groups of rats: $(O)$, mother-reared control; $(O)$, mother-reared undernourished; $(\mathbf{\Delta})$, artificially reared control; $(\Delta)$, artificially reared undernourished. Points are mean values with their standard errors represented by vertical bars. For details of rearing and nutrition, see pp. $246-247$.

Table 1. Probabilities associated with differences in the body-weight growth curves of four groups of rats with different early rearing and nutritional histories*

\begin{tabular}{|c|c|c|c|c|c|}
\hline $\begin{array}{l}\text { Postnatal } \\
\text { day }\end{array}$ & $\begin{array}{l}\text { Group... } \\
\text { Source of variance... }\end{array}$ & $\begin{array}{c}\mathrm{C} \\
\mathrm{MR} v \cdot \mathrm{AR}\end{array}$ & $\stackrel{\mathrm{U}}{\mathrm{MR} v \mathrm{AR}}$ & $\begin{array}{l}\mathrm{MR} \\
\mathrm{C} v . \mathrm{U}\end{array}$ & $\begin{array}{c}\text { AR } \\
C v . U\end{array}$ \\
\hline \multirow[t]{2}{*}{$5-25$} & $\begin{array}{l}\text { Growth curves not } \\
\text { "parallel' }\end{array}$ & $P<0.00001 \dagger$ & $P<0.01$ & $P<0.00001$ & $P<0.00001$ \\
\hline & $\begin{array}{l}\text { Weights averaged over } \\
5-25 \mathrm{~d} \text { differ }\end{array}$ & NS & NS & $P<0.00001$ & $P<0.00001$ \\
\hline \multirow[t]{2}{*}{$35-119$} & Growth curves not & $P<0.001$ & NS & $P<0.01$ & NS \\
\hline & $\begin{array}{l}\text { Weights averaged over } \\
35-119 \mathrm{~d} \text { differ }\end{array}$ & $P<0.01$ & $P<0.01$ & $P<0.00001$ & $P<0.00001$ \\
\hline
\end{tabular}

C, Well-fed control; U, undernourished; MR, mother-reared; AR, artificially reared; NS, not significant.

- For details, see pp. 246-247.

$\dagger$ Very highly significantly 'non-parallel'.

Body growth

The growth in body-weight of the four groups is shown in Figs. 1 and 2. Their growth curves are compared over the periods 5-25 and 35-119 d in Table 1 . There were very highly significant effects of nutrition on body-weight during both periods. Type of rearing, on the other hand, had no effect overall on body-weight between 5 and $25 \mathrm{~d}$ but did have a significant influence in the later period when the MR groups grew better than their respective AR comparison groups. In particular the growth curves for the MRC and ARC rats diverged from one another at this stage.

At autopsy at 39 weeks both of the formerly undernourished groups weighed less than 


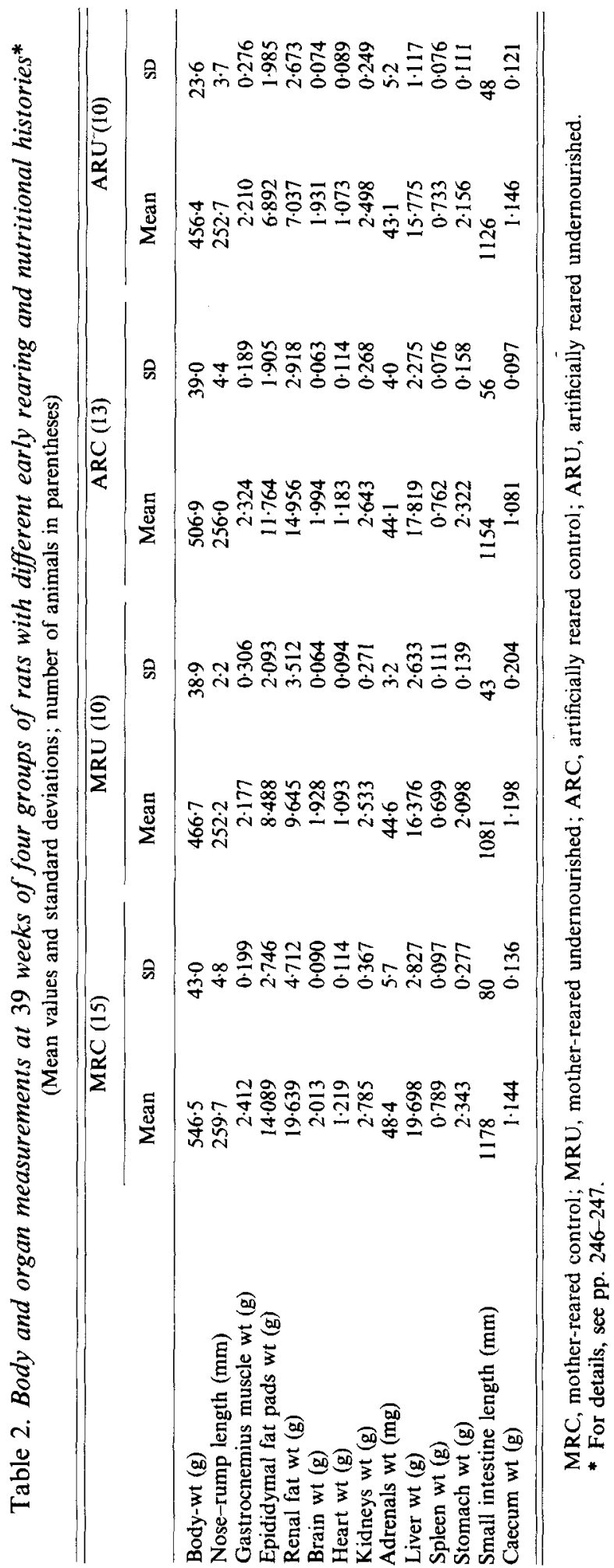


Table 3. Results of two-way analysis of variance (nutrition $\times$ rearing) in body and organ measurements of four groups of rats with different early rearing and nutritional histories at 39 weeks of age*

( $F$ values with df in parentheses)

\begin{tabular}{|c|c|c|c|c|c|c|}
\hline \multirow[b]{2}{*}{ Measure } & \multicolumn{2}{|c|}{ Nutrition } & \multicolumn{2}{|c|}{ Rearing } & \multicolumn{2}{|c|}{ Interaction } \\
\hline & $F(1,44)$ & $\begin{array}{c}\text { Statistical } \\
\text { significance } \\
P<\end{array}$ & $F(1,44)$ & $\begin{array}{c}\text { Statistical } \\
\text { significance: } \\
P<\end{array}$ & $F(1,44)$ & $\begin{array}{c}\text { Statistical } \\
\text { significance } \\
P<\end{array}$ \\
\hline \multicolumn{7}{|l|}{ Absolute values: } \\
\hline Body-wt & $35 \cdot 142$ & 0.001 & $6 \cdot 274$ & 0.05 & $1 \cdot 756$ & NS \\
\hline Nose-rump length & $21 \cdot 514$ & 0.001 & 2.634 & NS & $3 \cdot 143$ & NS \\
\hline Gastrocnemius muscle wt & $6 \cdot 355$ & 0.05 & 0.289 & NS & 0.755 & NS \\
\hline Epididymal fat pads wt & $63 \cdot 024$ & 0.001 & 9.593 & 0.01 & $0 \cdot 303$ & NS \\
\hline Renal fat wt & $70 \cdot 381$ & 0.001 & 13.025 & 0.001 & 0.938 & NS \\
\hline Brain wt & $11 \cdot 383$ & 0.01 & $0 \cdot 210$ & NS & $0 \cdot 240$ & NS \\
\hline Heart wt & $14 \cdot 669$ & 0.001 & 0.925 & NS & 0.078 & NS \\
\hline Kidneys wt & $5 \cdot 180$ & 0.05 & $1 \cdot 257$ & NS & $0 \cdot 371$ & NS \\
\hline Adrenals wt $\dagger$ & $3 \cdot 210$ & NS & $5 \cdot 016$ & 0.05 & 0.974 & NS \\
\hline Liver wt & $15 \cdot 118$ & 0.001 & 3.843 & NS & 0.843 & NS \\
\hline Spleen wt & $5 \cdot 180$ & 0.05 & 0.004 & NS & $1 \cdot 320$ & NS \\
\hline Stomach wt & $13 \cdot 210$ & 0.001 & 0.043 & NS & 0.474 & NS \\
\hline Small intestine length & 12.618 & 0.001 & 0.064 & NS & 3.726 & NS \\
\hline Caecum wt & $2 \cdot 068$ & NS & $2 \cdot 055$ & NS & 0.019 & NS \\
\hline \multicolumn{7}{|l|}{ Relative to body-wt: } \\
\hline Gastrocnemius muscle wt & $2 \cdot 801$ & NS & $1 \cdot 490$ & NS & 0.003 & NS \\
\hline Epididymal fat pads wt & $41 \cdot 521$ & 0.001 & 4.553 & 0.05 & $0 \cdot 108$ & NS \\
\hline Renal fat wt & $56 \cdot 752$ & 0.001 & $8 \cdot 057$ & 0.01 & 0.032 & NS \\
\hline Brain wt & 22.679 & 0.001 & 5.567 & 0.05 & $1 \cdot 134$ & NS \\
\hline Heart wt & $2 \cdot 089$ & NS & 1.837 & NS & 0.872 & NS \\
\hline Kidneys wt & $7 \cdot 293$ & 0.01 & 0.682 & NS & 0.128 & NS \\
\hline Adrenals wt $\dagger$ & $7 \cdot 286$ & 0.01 & 0.446 & NS & 0.020 & NS \\
\hline Liver wt & 0.643 & NS & 0.602 & NS & 0.076 & NS \\
\hline Spleen wt & $3 \cdot 267$ & NS & $3 \cdot 185$ & NS & 0.225 & NS \\
\hline Stomach wt & 4.239 & $0-05$ & $9 \cdot 647$ & 0.01 & 0.199 & NS \\
\hline Caecum wt & $22 \cdot 754$ & 0.001 & 0.022 & NS & 0.387 & NS \\
\hline
\end{tabular}

NS, not significant.

- For details, see pp. 246-247.

$\dagger$ df $1,43$.

their respective controls (Tables 2,3 and 4). In addition, the body-weight of the ARC animals was $7 \%$ less than that of the MRC group, but the MRU and ARU groups did not differ from one another (Table 5). Proportionately, nose-rump length was much less affected by treatment than body-weight, with no difference between groups being greater than 3\%. Nevertheless, both the MRU and ARC groups were significantly shorter than MRC rats (Tables 2, 3, 4 and 5).

\section{Organ measures at 39 weeks}

The mean absolute values for the four groups of rats are given in Table 2. Analysis of variance revealed significant effects of nutrition on ten of the twelve organs measured, but significant effects of rearing on only three organs (Table 3 ). The weights of the epididymal and renal fat depots were affected by both nutrition and rearing, and that of the adrenals by rearing alone. Expressing organ weights as a proportion of body-weight reduced the 
Table 4. Body and organ measurements (absolute and relative values ( $\mathrm{g} / \mathrm{kg}$ body-weight)) at 39 weeks of mother-reared $(M R)$ and artificially reared $(A R)$ rats which had been undernourished $(U)$ early in life, expressed as a percentage of those of their respective wellnourished control (C) groups †

\begin{tabular}{|c|c|c|c|c|}
\hline & \multicolumn{2}{|c|}{ MRU (\% MRC) } & \multicolumn{2}{|c|}{ ARU (\% ARC) } \\
\hline & $\begin{array}{l}\text { Absolute } \\
\text { values }\end{array}$ & $\begin{array}{c}\mathrm{g} / \mathrm{kg} \\
\text { body-wt }\end{array}$ & $\begin{array}{l}\text { Absolute } \\
\text { values }\end{array}$ & $\begin{array}{c}\mathrm{g} / \mathrm{kg} \\
\text { body-wt }\end{array}$ \\
\hline Body-wt & $85^{* * *}$ & - & $90^{* *}$ & - \\
\hline Nose-rump length & $97^{* * *}$ & - & 99 & - \\
\hline Gastrocnemius muscle wt & $90^{*}$ & 105 & 95 & 105 \\
\hline Epididymal fat pads wt & $60^{* * *}$ & $71 * * *$ & $59^{* * * *}$ & $65^{* * *}$ \\
\hline Renal fat wt & $49^{* * *}$ & $58 * * *$ & $47^{* * *}$ & $52^{* * *}$ \\
\hline Brain wt & $96^{*}$ & $112 * * *$ & $97^{*}$ & $107^{*}$ \\
\hline Heart wt & $90^{* *}$ & 105 & $91^{*}$ & 101 \\
\hline Kidneys wt & 91 & 107 & 95 & 105 \\
\hline Adrenals wt & 92 & 108 & 98 & 109 \\
\hline Liver wt & $83^{* *}$ & 97 & $89^{*}$ & 99 \\
\hline Spleen wt & $89^{*}$ & 104 & 96 & 107 \\
\hline Stomach wt & $90^{*}$ & 105 & $93^{*}$ & 103 \\
\hline Small intestine length & $92 * *$ & - & 98 & - \\
\hline Caecum wt & 105 & $123^{* *}$ & 106 & $118^{* * *}$ \\
\hline
\end{tabular}

* $P<0.05,{ }^{* *} P<0.01,{ }^{* * *} P<0.001$ (Student's $t$ test).

+ For details of rearing and nutrition, see pp. 246-247.

Table 5. Body and organ measurements (absolute and relative values $(\mathrm{g} / \mathrm{kg}$ body-weight)) at 39 weeks of artificially reared $(A R)$, control $(C)$ and undernourished $(U)$ rats, expressed as a percentage of those of their respective mother-reared $(M R)$ comparison groups $\dagger$

\begin{tabular}{|c|c|c|c|c|}
\hline & \multicolumn{2}{|c|}{$\operatorname{ARC}(\% \mathrm{MRC})$} & \multicolumn{2}{|c|}{ ARU (\% MRU) } \\
\hline & $\begin{array}{c}\text { Absolute } \\
\text { values }\end{array}$ & $\begin{array}{c}\mathrm{g} / \mathrm{kg} \\
\text { body-wt }\end{array}$ & $\begin{array}{c}\text { Absolute } \\
\text { values }\end{array}$ & $\begin{array}{c}\mathrm{g} / \mathrm{kg} \\
\text { body-wt }\end{array}$ \\
\hline Body-wt & $93^{*}$ & - & 98 & - \\
\hline Nose-rump length & $99^{*}$ & - & 100 & - \\
\hline Gastrocnemius muscle wt & 96 & 104 & 102 & 104 \\
\hline Epididymal fat pads wt & $83^{*}$ & 91 & 81 & 83 \\
\hline Renal fat wt & $76^{* *}$ & $84^{*}$ & 73 & 75 \\
\hline Brain wt & 99 & $107^{*}$ & 100 & 102 \\
\hline Heart wt & 97 & 104 & 98 & 100 \\
\hline Kidneys wt & 95 & 102 & 99 & 101 \\
\hline Adrenals wt & $91^{*}$ & 97 & 97 & 99 \\
\hline Liver wt & 90 & 98 & 96 & 99 \\
\hline Spleen wt & 97 & 104 & 105 & 107 \\
\hline Stomach wt & 99 & $107^{*}$ & 103 & 105 \\
\hline Small intestine length & 98 & - & $104^{*}$ & - \\
\hline Caecum wt & 94 & 102 & 96 & 97 \\
\hline
\end{tabular}

* $P<0.05, * * P<0.01$ (Student's $t$ test).

+ For details of rearing and nutrition, see pp. 246-247. 
number of organs for which there were significant effects of nutrition to seven of eleven organs, indicating that the weights of four organs (gastrocnemius muscle, heart, liver and spleen) were appropriate for body-weight in previously undernourished animals (Table 3). The relative weights of the two fat depots were significantly affected by both nutrition and rearing, as were those of brain and stomach. Relative kidney, adrenal and caecum weights showed main effects of nutrition only.

The greatest effects of nutrition and rearing on both absolute and relative values were those on the two fat depots. Epididymal and renal fat pad weights were about $40-50 \%$ lower in previously undernourished rats than in well-fed rats and about $20 \%$ lower in AR rats than in MR animals (Tables 4 and 5). Formerly undernourished rats had a 3-4\% deficit in brain weight, which converted to a significant excess when expressed against bodyweight (Table 4). That is, brain growth was 'spared' relative to that of the body as a whole. Unexpectedly, so too was growth of the caecum.

\section{DISCUSSION}

The effects of undernutrition from 5 to $25 \mathrm{~d}$ on subsequent body and organ growth were much as anticipated. Growth in body-weight failed to catch up during the period of refeeding and, indeed, the growth curves of the well-fed rats diverged from those of the undernourished animals in agreement with several earlier investigations (Widdowson \& McCance, 1960; Smart et al. 1974; Williams et al. 1974). Body length was much less affected by previous undernutrition than body-weight. By 39 weeks the effect of nutrition, though statistically very highly significant, was only $1-3 \%$. Judging by other studies, it is highly likely that catch-up did occur in length, in the sense of the length deficit diminishing during nutritional rehabilitation (Smart et al. 1974; Williams et al. 1974). Hence in terms of weight-for-length, the formerly undernourished rats were leaner than their controls, and this is borne out by their considerably smaller fat depot weights. The 30-50\% deficits relative to whole-body weight concur with other findings for rats refed after undernutrition during the suckling period (Smart et al. 1974; Stephens, 1980). Though undernutrition resulted in deficits of 3-4\% in brain weight, the familiar 'sparing' effect was evident when brain weight was expressed relative to body-weight (Winick \& Noble, 1966; Dobbing \& Sands, 1971; Smart et al. 1974). The high relative weight of caecum in the previously undernourished animals was unexpected and is difficult to account for. The presence or absence of a gut flora is known to influence caecal growth (Gordon \& Pesti, 1971) and, hence, one might speculate that undernutrition followed by refeeding results in a different gut flora from continuously adequate nutrition, which may have implications for the growth and development of the caecum.

Given that it was one of the aims of the present experiment to produce rats by AR which were as well grown as MR animals, it is encouraging that there were few significant effects of type of rearing (Table 3). Indeed, three of five significant differences between ARC and MRC animals (Table 5) are likely to be related, in that the lower weight of the epididymal and renal fat pads in ARC rats probably indicates an overall fat deficiency which may well be an important component of their deficit in whole-body-weight. Assuming that fat accounts for $20 \%$ of body-weight and that the ARC rats had $20 \%$ less fat than the MRC rats, it can be calculated that more than half the ARC deficit in body-weight was attributable to their lesser fat content. It is perhaps noteworthy that even the ARU rats tended to be less fat than their MRU comparison group (Table 5).

The reason for the relative leanness of the present AR rats is probably to be found in the composition of the expressed rats' milk (for method of collection, see Tonkiss et al. 1987) which they were given in the early stages of AR. To recapitulate, the dietary regime used 
here was $3 \mathrm{~d}$ on expressed rats' milk only, followed by a series of mixtures of rats' milk and milk-substitute, increasing in milk-substitute content till $17 \mathrm{~d}$ of age when milk-substitute only was given. Since rearing the present rats, we have had determinations made of the protein, lactose and fat content of pooled samples of our rats' milk. The values were (g/l): protein 70, lactose 27, fat 61 (R. M. Mabon and E. Y. Brechany, unpublished results), which compares with $(\mathrm{g} / \mathrm{l})$ protein 92 , carbohydrate 30 , fat 175 in milk from rats $5-9$ d into lactation (Keen et al. 1981). That is, the fat content of our expressed rats' milk was extremely low, being only about one-third of that reported by Keen et al. (1981). It seems likely that the principal reason for this is the $16-19 \mathrm{~h}$ interval between removal of the pups and milking employed here to maximize yield by volume, compared with the $2-4 \mathrm{~h}$ interval of Keen et al. (1981), since there is evidence that lengthy interruption of suckling reduces the fat content of milk (Naismith et al. 1969). It is highly likely, therefore, that our AR pups received much less fat than their MR counterparts during the 1st week or so of AR, which difference may have contributed to their poorer growth in body-weight at that time (Fig. 1) and to their subsequent leanness. If so, it is a remarkable finding that so short a period on a low-fat diet ( $12 \mathrm{~d}$ but progressing over that period from very-low to marginally low in fat) can have such a substantial, lasting effect on body fatness.

It is a requirement of undernutrition experiments with AR animals that there should be a well-grown ARC group. A previous attempt in which the pups were given the much-used Messer milk-substitute (Messer et al. 1969) fell short in this respect (Smart et al. 1983). The present rearings were much more successful in that ARC rats were produced which differed in only a few respects from their MR controls. The present ARC rats showed no significant deficits in the weights of the brain and gastrocnemius muscle, in contrast to the earlier batch, and much improved growth in nose-rump length and adrenal weight. Also, they were leaner than their MR controls, unlike the earlier ARC rats which were much fatter. On this and other evidence (Tonkiss et al. 1987) we are encouraged to think that the present dietary regimen, starting AR on rats' milk and changing to milk-substitute through a series of mixtures of increasing milk-substitute content, is much more satisfactory than rearing on any milk-substitute known to us, alone. Improvement of the fat content of the expressed rats' milk is clearly advisable, either by direct supplementation with fat or by collecting the milk (in small quantities) after a shorter interval of mother-pup separation.

This research was supported by the Medical Research Council and the National Fund for Research into Crippling Diseases. The authors are very grateful to Professor J. Edmond and Ms'N. S. Auestad (Department of Biological Chemistry, UCLA) for supplying us with rat milk-substitute, to Mr R. M. Mabon and Miss E. Y. Brechany (Hannah Research Institute, Ayr) for analysis of the composition of the rats' milk, and to $\mathrm{Mr} \mathrm{A}$. C. C. Gibbs (Community Medicine) and Dr V. F. Hillier (Computational Group, Manchester Medical School) for their advice and assistance with statistical analysis.

\section{REFERENCES}

Dobbing, J. (1981). In The Molecular Basis of Neuropathology, pp. 221-233 [R. H. S. Thompson and A. N. Davison, editors]. London: Edward Arnold.

Dobbing, J. \& Sands, J. (1971). Biology of the Neonate 19, 363-378.

Gordon, H. A. \& Pesti, L. (1971). Bacteriological Reviews 35, 390-429.

Hall, W. G. (1975). Science, New York 190, 1313-1315.

Keen, C. L., Lönnerdal, B., Clegg, M. \& Hurley, L. S. (1981). Journal of Nutrition 111, 226-236.

Kennedy, G. C. (1957). Journal of Endocrinology 16, 9-17.

Levine, S. \& Wiener, S. (1976). Advances in Pediatrics 22, 113-136.

Messer, M., Thoman, E. B., Terrasa, A. G. \& Dallman, P. R. (1969). Journal of Nutrition 98, 404-410.

Naismith, D. J., Mittwoch, A. \& Platt, B. S. (1969). British Journal of Nutrition 23, 683-693. 
Smart, J. L. (1980). Developmental Psychobiology 13, 431-433.

Smart, J. L., Adlard, B. P. F. \& Dobbing, J. (1974), Biology of the Neonate 25, 135-150.

Smart, J. L., Dobbing, J., Adlard, B. P. F., Lynch, A. \& Sands, J. (1973). Journal of Nutrition 103, $1327-1338$.

Smart, J. L., Stephens, D. N. \& Katz, H. B. (1983). British Journal of Nutrition 49, 497-506.

Smart, J. L., Stephens, D. N., Tonkiss, J., Auestad, N. S. \& Edmond, J. (1984). British Journal of Nutrition 52, 227-237.

Smart, J. L. \& Tonkiss, J. (1985). Proceedings of the Nutrition Society 44, 100A.

Smart, J. L., Tonkiss, J. \& Massey, R. F. (1987). Neuroscience Letters Supplement 29 S105.

Stephens, D. N. (1980). British Journal of Nutrition 44, 215-227.

Tonkiss, J., Smart, J. L., Auestad, N. S. \& Edmond, J. (1985). Journal of Pediatric Gastroenterology and Nutrition 4, 818-825.

Tonkiss, J., Smart, J. L. \& Massey, R. F. (1987). British Journal of Nutrition 57, 3-11.

University of Manchester Regional Computer Centre (1982). Statistical Package for the Social Sciences Additional Procedures, 5. Version 8 on the CDC 7600.

Whatson, T. S. \& Smart, J. L. (1978). Physiology and Behavior 20, 749-753.

Widdowson, E. M. \& McCance, R. A. (1960). Proceedings of the Royal Society B, 152, 188-206.

Williams, J. P. G., Tanner, J. M. \& Hughes, P. C. R. (1974). Pediatric Research 8, 149-156.

Winick, M. \& Noble, A. (1966). Journal of Nutrition 89, 300-306. 